\title{
Angiotensin II Metabolism by Tissues from Developing Rats
}

\author{
K. B. WALLACE, S. OPARIL, AND M. D. BAILIE ${ }^{(24)}$ \\ Departments of Physiology and Pediatrics/Human Development, Michigan State University, East Lansing, Michigan \\ [K. B. W.. M. D. B.], and School of Medicine, Department of Medicine and Cardiovascular Research and Training \\ Center University of Alabama, Birmingham, Alabama, USA [ S. O.]
}

\section{Summary}

Asp ${ }^{1}-{ }^{125} \mathrm{I}-\mathrm{Tyr}^{4}$-angiotensin II $\left({ }^{125} \mathrm{I}-\mathrm{AII}\right)$ was degraded during incubation with rat plasma or homogenates of liver or kidney. The electrophoretic profile of peptide fragments revealed that the disappearance of ${ }^{125}$ I-AII was first order and was accompanied by an accumulation of ${ }^{125} \mathrm{I}$-tyrosine in the incubation medium. The only other metabolites of angiotensin AII detectable by peptide mapping were the amino-terminus tetrapeptide and the carboxyterminus hexapeptide. The appearance of these fragments was highly variable, suggesting that endopeptidases did not constitute the ultimate cleavage of angiotensin II hydrolysis. The half-life of ${ }^{125}$-AII in plasma or liver homogenates did not change with age (approximately 8 to 12 and 6 to $9 \mathrm{~min}$, respectively). In contrast, the rate of disappearance of ${ }^{125} \mathrm{I}$-AII in homogenates of rat kidney depended upon the age of the rat from which the tissue was obtained. The half-life of ${ }^{125}$ AII decreased three-fold (from approximately 8.3 to $2.8 \mathrm{~min}$ ) between $2 \mathrm{wk}$ after birth and adult (approximately $8 \mathrm{wk}$ ). This increase in the rate of metabolism of ${ }^{125}$ I-AII was accompanied by a concomitant two-fold, age-related increase in the rate of appearance of ${ }^{125} \mathrm{I}$-tyrosine in the reaction mixture containing renal tissue.

\section{Speculation}

Age-related differences in the activities of angiotensinase enzymes may be of considerable importance in regulating the concentration of angiotensin II in plasma and tissues of developing animals. When viewed in context of changes in renin and converting enzyme activities in rats, the increase in the rate of metabolism of angiotensin II is the only available evidence consistent with the decrease in plasma angiotensin II concentration between 6 and 8 wk of age.

The kinetics of the renin-angiotensin system in adult animals has been extensively investigated; however, much remains to be determined concerning the integration of this pressor system in neonates. It has been suggested that the renin-angiotensin system may be more influential in regulating body fluid volume and electrolyte composition in immature animals compared to adults $(9,15)$.

Large differences in the stoichiometry of the renin-angiotensin system early during development have been well established in several species $(2,9,12,17,19)$. Both the activity and the concentration of renin in plasma are severalfold greater in newborns than in adults $(2,5,12,19)$. In a few species such as the dog, rat, and rabbit, plasma renin concentration increases initially after birth and then gradually declines thereafter to adult values $(3,4,19)$. The age-related changes in renin activity have been attributed to the changes in the concentration of the enzyme rather than to differences in the kinetics of the renin-substrate interaction (16). The activity of angiotensin-converting enzyme in rats, on the other hand, appears late during gestation and increases throughout prenatal and postnatal development, reaching adult values at approximately 6 wk of age $(17,18)$.

In rats, plasma angiotensin II (AII) concentration increases between 3 and 7 wk of age (19). This increase has been correlated with an age-related increase in the rate of conversion of angiotensin I to AII during this same period of development $(17,19,20)$. The concentration of AII in plasma decreases after the sixth wk postpartum, until adult values are reached by the eighth wk of age (19). In view of the changes in plasma renin activity and angiotensin-converting enzyme during this period, the decrease in plasma AII concentration between 6 and $8 \mathrm{wk}$ was assumed to represent an age-related increase in the rate of clearance of angiotensin from the circulation $(1,12,19)$.

It was the purpose of this investigation to examine the agerelated changes in the rate of degradation of AII. Because angiotensin is inactivated in a variety of vascular beds $(6,8)$, the halflife of AII was determined in several tissues. It was also of interest to compare and contrast the metabolic profile of peptide fragments formed from AII in different tissues at various ages.

\section{MATERIALS AND METHODS}

The metabolism of synthetic Asp ${ }^{1}-{ }^{125} \mathrm{I}_{-}-\mathrm{Tyr}^{4}$-angiotensin II $\left({ }^{125} \mathrm{I}\right.$ AII) (New England Nuclear) was examined in tissues of male Sprague-Dawley rats (Spartan Research Animals, Inc., Haslett, MI). All animals were maintained on normal laboratory diet (Wayne Lab Blocks) and tap water ad libitum. Each litter of 2-wkold rats was pooled to obtain sufficient tissue for a single determination. Tissues from two 5 -wk-old rats were combined for each determination. Adequate tissue was obtained from $8 \mathrm{wk}$ and adult rats (approximately $12 \mathrm{wk}$ ) allowing for each animal to represent a single measurement.

All animals were killed by decapitation, and blood was collected from the severed neck vessels into a chilled vial containing heparin (1000 units $/ \mathrm{ml}$ ) to prevent coagulation. The plasma was separated by centrifugation $\left(1000 \times g\right.$ for $10 \mathrm{~min}$ at $\left.4^{\circ} \mathrm{C}\right)$ and stored frozen at $-20^{\circ} \mathrm{C}$ until assayed. The liver and kidneys were perfused with cold isotonic $\mathrm{NaCl}$ solution $(0.9 \%)$ through the portal vein or the renal artery, respectively. Once cleared of blood, the tissues were excised and homogenized (Polytron, Brinkmann Instruments) in 10 volumes $(\mathrm{ml} / \mathrm{g})$ cold $0.1 \mathrm{M}$ Tris- $\mathrm{HCl}$ buffer $(\mathrm{pH} \mathrm{7.4)}$. The tissues were further disrupted by sonification (Branson Sonifier), and the resulting sonicate was stored at $-20^{\circ} \mathrm{C}$ until assayed for angiotensinase activity.

The angiotensinase reaction mixture $(1.0 \mathrm{ml})$ consisted of radiolabelled AII $(20 \mu \mathrm{Ci} / \mathrm{pg} ; 50 \mathrm{pg} / \mathrm{ml})$ and tissue sonicates in 0.1 $\mathrm{M}$ Tris- $\mathrm{HCl}$ buffer ( $\mathrm{pH} 7.4)$. Plasma was added such that the final dilution was $1: 10$ in the incubation medium. Preliminary experiments established that dilution of both liver and kidney tissue to $1: 2000$ in the final reaction mixture was optimal for establishing appropriate conditions for measuring ${ }^{125}$ I-AII metabolism. The initial dilution of the tissue in the homogenate $(1: 10)$ was included in the final dilution factor. 
The incubation medium containing diluted tissue or plasma enzyme was preincubated at $37^{\circ} \mathrm{C}$ for $10 \mathrm{~min}$ before addition of ${ }^{125}$ I-AII to initiate the reaction. At the appropriate times during the reaction, the mixtures were vortexed, and a small aliquot (50 $\mu$ ) was rapidly transferred to a chilled vial containing $5.4 \mathrm{mM}$ dimercaprol and $1.1 \mathrm{mM}$ 8-hydroxyquinoline which have proven to effectively prevent further enzymatic degradation of angiotensin (data not shown). The aliquots of the reaction were then stored frozen until analyzed for the distribution of radioactivity in the peptide fragments formed from the hydrolysis of ${ }^{125}$ I-AII.

Peptide mapping was performed by high-voltage paper electrophoresis as described in detail previously (10). In brief, the samples were spotted on Whatman $3 \mathrm{~mm}$ paper and subjected to electrophoresis $(4000 \mathrm{~V}$ for $\mathrm{l} \mathrm{hr})$ using pyridine acetate as buffer $(\mathrm{pH}$ 3.6). The chromatograms were dried, cut into $1 \mathrm{~cm}$ strips, and counted in a gamma counter. The identity of the separated peptides was determined by comparison of their migration properties to those of known peptide standards prepared by selective enzymatic digestion of AII (10).

Statistical significance was determined by the Student $t$ test for individual comparisons (13). The 0.05 level of probability was used as the criterion of significance.

\section{RESULTS}

The radiolabeled peptide used in this investigation was greater than $99 \%$ radiochemically pure ${ }^{125} \mathrm{I}$-AII. Incubation of $50 \mathrm{pg} / \mathrm{ml}$ ${ }^{125} \mathrm{I}-\mathrm{AII}$ in the absence of tissue or plasma resulted in no significant spontaneous loss of the peptide. The concentration of ${ }^{125} \mathrm{I}-\mathrm{AII}$ at the end of $15 \mathrm{~min}$ of incubation was consistently greater than $95 \%$ of the initial concentration. The slight loss of ${ }^{125} \mathrm{I}$-AII was not associated with any distinct pattern of degradation and the variability was within the experimental error.

When ${ }^{125}$ I-AII was incubated with either plasma or whole homogenates of liver or kidney, the concentration of the radiolabeled octapeptide decreased with time (Fig. 1). This was accom- panied by a gradual increase in the area under the peaks representing shorter peptide fragments (tyr, 3-8, 1-4). The sum of the area under all peaks was consistently greater than $95 \%$ that of the initial ${ }^{125}$ I-AII peak. This high percent recovery of radioactivity was observed in all instances regardless of the tissue or time of incubation.

The decrease in the area under the ${ }^{125}$ I-AII peak was quantitative and nearly complete after $15 \mathrm{~min}$ of incubation (Fig. 1). In the representative case shown (adult renal tissue), the percent of the initial ${ }^{125}$ I-AII concentration decreased from $90 \%$ of the total radioactivity at time zero to less than $5 \%$ in the 15 min sample. In contrast, the fraction of the initial AII concentration which migrated as ${ }^{125} \mathrm{I}$-tyrosine $\left({ }^{125} \mathrm{I}\right.$ - $\left.\mathrm{Tyr}\right)$ increased throughout the incubation period until by $15 \mathrm{~min}$ radiolabeled tyrosine accounted for approximately $75 \%$ of the initial ${ }^{125}$ I-AII concentration (Fig. 1).

The two peaks furthest from the origin, labeled as (3-8) and (14) (Fig. 1), were identified as the carboxy-terminus hexapeptide and the amino-terminus tetrapeptide, respectively (10). Identification of these peaks was performed by incubating radiolabeled AII with purified preparations of trypsin and chymotrypsin, respectively, and then analyzing the resulting peptide fragments electrophoretically (10). The tryptic peptide (3-8) was observed in most reactions in a concentration greater than that of the chymotryptic fragment (Table 1). Although no distinct differences in the rate of formation of these fragments were observed between ages, both peptides invariably accounted for a smaller portion of the radioactivity in plasma compared to that in renal or hepatic incubation mixtures. The absence of a defined pattern for the appearance and the relatively low concentration of these fragments suggested that the tetra- and hexapeptides were minor or intermediate products in the enzymatic digestion of ${ }^{125} \mathrm{I}$-Angiotensin II. No des-Asp-AII was identified among the metabolites.

The disappearance of ${ }^{125} \mathrm{I}-\mathrm{AII}$ from the reaction mixture proceeded in a first-order fashion, being logarithmically linear over the time of incubation (Fig. 2). The disappearance curves represent data obtained with renal extracts; however, similar linear plots

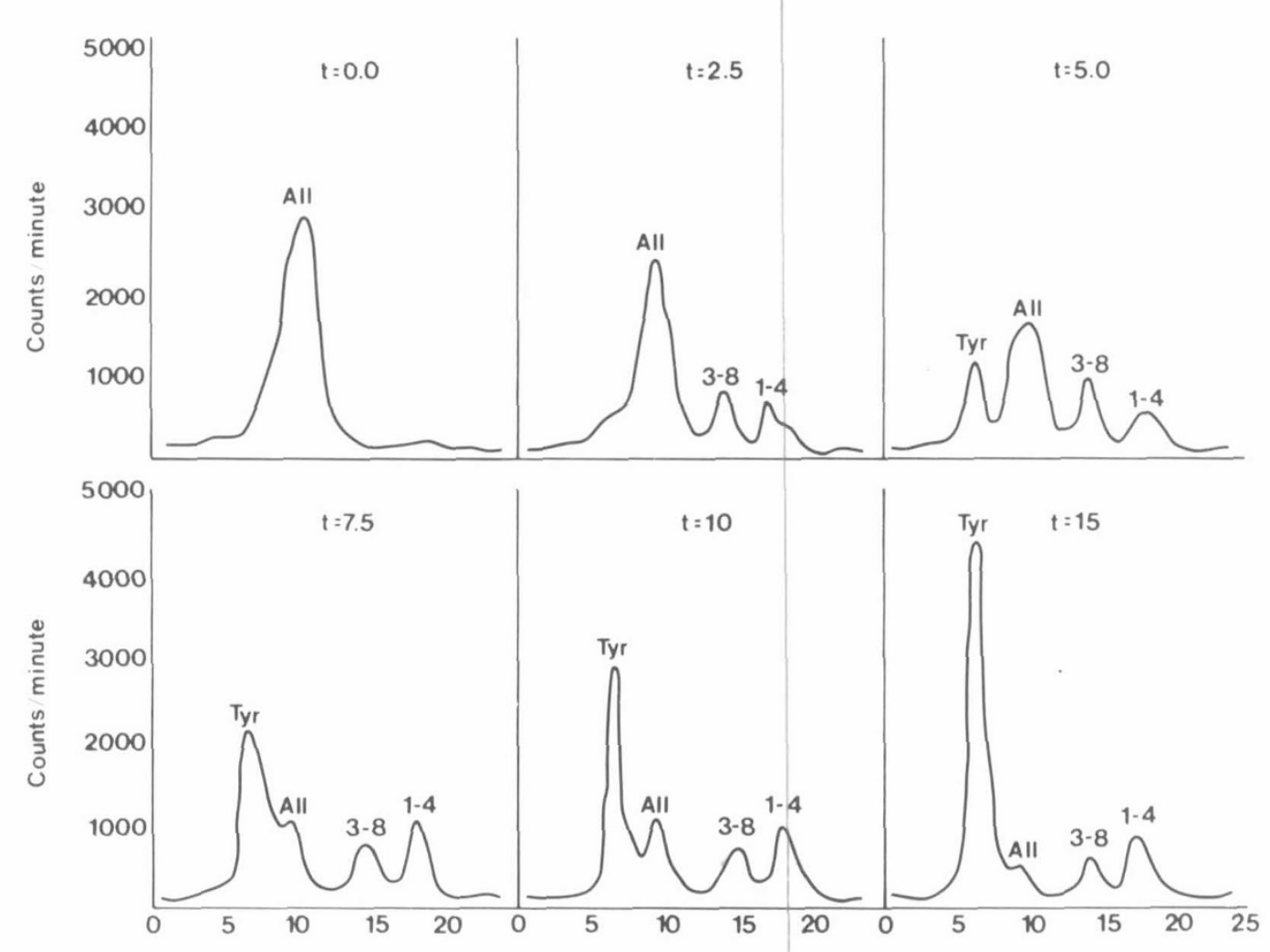

Fig. I. Time-course for the appearance of peptide fragments of ${ }^{125} \mathrm{I}-\mathrm{AlI}$ as determined by high-voltage paper electrophoresis. ${ }^{125} \mathrm{I}-\mathrm{AII}$ was incubated in vitro with homogenates of adult rat kidneys. The migration of ${ }^{125} \mathrm{I}-\mathrm{AII}$ and ${ }^{125} \mathrm{I}-\mathrm{Tyr}$ along with the $1-4$ tetrapeptide and the $3-8$ hexapeptide is shown. The time of incubation is indicated by $t$ expressed in minutes. 
Table 1. Peptide fragments of AII degradation during development ${ }^{1}$

\begin{tabular}{|c|c|c|c|c|c|c|c|}
\hline \multirow{2}{*}{ Age } & \multirow{2}{*}{$\begin{array}{l}\text { Time } \\
(\mathrm{min})\end{array}$} & \multicolumn{2}{|c|}{ Plasma } & \multicolumn{2}{|c|}{ Kidney } & \multicolumn{2}{|c|}{ Liver } \\
\hline & & $3-8^{2}$ & $1-4$ & $3-8$ & $1-4$ & $3-8$ & $1-4$ \\
\hline \multirow[t]{6}{*}{$2 w k$} & 0 & $10.8(0-23)$ & $0.0(0)^{3}$ & $3.8(0-12)$ & $4.4(0-9)$ & $1.2(0-5)$ & $0.0(0)$ \\
\hline & 2.5 & & & $14.5(10-25)$ & $9.7(4-12)$ & $13.9(13-16)$ & $2.9(0-6)$ \\
\hline & 5.0 & $9.3(0-21)$ & $0.1(0-1)$ & $13.3(4-31)$ & $15.4(9-27)$ & $18.6(14-24)$ & $8.8(5-15)$ \\
\hline & 7.5 & & & $16.8(9-32)$ & $14.7(12-18)$ & $16.8(0-25)$ & $8.6(0-16)$ \\
\hline & 10.0 & $13.4(0-15)$ & $2.3(0-4)$ & $14.5(10-27)$ & $17.2(12-28)$ & $22.9(18-27)$ & $8.1(0-14)$ \\
\hline & 15.0 & $0.0(0)$ & $0.0(0)$ & $14.9(10-24)$ & $13.1(9-16)$ & $27.7(25-31)$ & $11.2(1-19)$ \\
\hline \multirow[t]{6}{*}{$5 \mathrm{wk}$} & 0 & $0.0(0)$ & $21.3(11-35)$ & $8.6(6-12)$ & $0.0(0)$ & $0.0(0)$ & $0.0(0)$ \\
\hline & 2.5 & & & $16.9(15-20)$ & $7.7(6-10)$ & $9.0(6-16)$ & $7.5(6-9)$ \\
\hline & 5.0 & $3.6(0-15)$ & $0.2(0-1)$ & $15.0(11-19)$ & $7.7(5-9)$ & $11.4(0-20)$ & $12.9(8-16)$ \\
\hline & 7.5 & & & $12.7(10-17)$ & $6.0(0-9)$ & $12.6(0-21)$ & $13.8(10-18)$ \\
\hline & 10.0 & $12.0(11-13)$ & $0.6(0-2)$ & $12.9(10-16)$ & $7.6(6-9)$ & $5.6(0-22)$ & $3.6(0-11)$ \\
\hline & 15.0 & $6.4(0-18)$ & $0.5(0-2)$ & $8.7(8-10)$ & $3.4(0-6)$ & $11.9(0-18)$ & $11.6(8-14)$ \\
\hline \multirow[t]{6}{*}{$8 w k$} & 0 & $0.0(0)$ & $0.0(0)$ & $10.4(0-20)$ & $1.5(0-3)$ & $4.0(0-16)$ & $2.3(0-9)$ \\
\hline & 2.5 & & & $6.7(0-13)$ & $3.6(0-10)$ & $11.0(10-11)$ & $12.7(11-15)$ \\
\hline & 5.0 & $0.0(0)$ & $0.0(0)$ & $9.3(6-15)$ & $1.9(0-6)$ & $8.5(0-13)$ & $16.3(13-21)$ \\
\hline & 7.5 & & & $5.6(2-9)$ & $0.6(0-2)$ & $13.9(8-23)$ & $16.4(14-20)$ \\
\hline & 10.0 & $0.0(0)$ & $0.0(0)$ & $4.9(3-8)$ & $0.0(0)$ & $13.5(7-25)$ & $15.8(7-23)$ \\
\hline & 15.0 & $0.0(0)$ & $0.0(0)$ & $4.7(2-6)$ & $1.0(0-3)$ & $13.3(6-24)$ & $17.1(12-21)$ \\
\hline \multirow[t]{6}{*}{ Adult } & 0 & $8.0(0-12)$ & $0.0(0)$ & $9.2(6-130$ & $0.4(0-1)$ & $7.8(0-12)$ & $0.5(0-1)$ \\
\hline & 2.5 & & & $23.5(14-31)$ & $5.3(1-9)$ & $16.6(12-21)$ & $15.8(13-18)$ \\
\hline & 5.0 & $11.8(10-14)$ & $3.5(1-9)$ & $12.1(2-27)$ & $2.9(2-5)$ & $12.8(10-15)$ & $17.6(14-19)$ \\
\hline & 7.5 & & & $16.9(13-23)$ & $4.5(0-9)$ & $11.3(7-16)$ & $20.2(17-23)$ \\
\hline & 10.0 & $13.7(12-15)$ & $0.6(0-2)$ & $9.4(5-18)$ & $0.8(0-2)$ & $9.0(7-13)$ & $22.0(17-26)$ \\
\hline & 15.0 & $14.0(8-18)$ & $1.8(0-4)$ & $6.2(2-9)$ & $0.7(0-2)$ & $6.6(6-8)$ & $22.2(16-27)$ \\
\hline
\end{tabular}

\footnotetext{
${ }^{1}$ Values represent the mean of 3 determinations.

23-8 and 1-4 represent the carboxy-terminus hexapeptide and the amino-terminus tetrapeptide of angiotension AII, respectively.

${ }^{3}$ Numbers in parentheses, range of values observed for each determination. The units are percent of the total radioactivity.
}

were obtained with plasma and hepatic tissue at every age examined (data not shown). The rate of disappearance of ${ }^{125} \mathrm{I}-\mathrm{AII}$ in the presence of renal tissue increased with age (Fig. 2). The slope of the lines increased from $-0.03 \mathrm{log} \% / \mathrm{min}$ in renal extracts from 2 -wk-old rats to $-0.13 \mathrm{log} \% / \mathrm{min}$ in adults. All lines were significantly linear as determined by linear regression, the method of least squares (13).

The half-life of $\left({ }^{125}\right.$-I)-AII was determined from the slope of the line describing the disappearance of the radiolabel in the AII peak. No age-related difference in the half-life of AII was observed for the reaction in either plasma or homogenates of liver (Fig. 3). In contrast, the rate of disappearance of ${ }^{125} \mathrm{I}$-AII from reaction mixtures containing renal tissue was dependent on the age of the rat from which the tissue was obtained (Figs. 2 and 3). The halflife of ${ }^{125} \mathrm{I}$-AII in renal tissue decreased from $8.4 \pm 1.2 \mathrm{~min}$ in 2 wk-old rats to $4.0 \pm 0.7 \mathrm{~min}$ in 8 -wk-old rats and $2.8 \pm 1.8 \mathrm{~min}$ in adults.

High-voltage paper electrophoresis demonstrated that the major product of ${ }^{125} \mathrm{I}$-AII degradation was free ${ }^{125} \mathrm{I}-\mathrm{Tyr}$ (Fig. 1). It is not fortuitous, therefore, that the age-related changes in the half-life of ${ }^{125}$ I-AII were accompanied by similar differences in the rate of appearance of ${ }^{125} \mathrm{I}$-Tyr in the reaction mixture (Fig. 4). No differences were observed in the time at which ${ }^{125} \mathrm{I}$-Tyr accounted for $50 \%$ of the initial ${ }^{125}$ I-AII concentration $\left(\mathrm{T}_{1 / 2}\right.$ - $\left.\mathrm{Tyr}\right)$ in plasma or homogenates of liver. On the other hand, the rate at which ${ }^{125} \mathrm{I}$ Tyr increased to represent $50 \%$ of the zero-time ${ }^{125}$ I-AII concentration was significantly more rapid in the presence of renal tissue from adult rats compared to renal tissue from younger animals (Fig. 4). The $T_{1 / 2}$-Tyr in kidneys from 2-wk-old rats was $25.0 \pm$ $5.4 \mathrm{~min}$, whereas that at 5 and $8 \mathrm{wk}$ of age was $16.0 \pm 0.8$ and 15.8 $\pm 1.9 \mathrm{~min}$, respectively. The $\mathrm{T}_{1 / 2}$-Tyr in homogenates of adult kidneys was $10.9 \pm 1.2 \mathrm{~min}$.

\section{DISCUSSION}

The concentration of AII in plasma of 2-wk-old rats is relatively low and increases to maximum values observed between 5 and 6 wk of age (19). Plasma AII concentration decreases thereafter to adult values by the eighth wk postpartum. Because converting enzyme activity increases with age (14, 17, 18, 20, 21), the increase in plasma AII concentration early during development (4 to $6 \mathrm{wk}$ ) may be mediated by the age-related increase in the rate of conversion of angiotensin I to AII. The subsequent decrease in the concentration of AII between 6 and 8 wk of age, however, is inconsistent with either the unchanging plasma renin activity or the continuing increase in angiotensin-converting enzyme activity during this period $(17,19)$. This discrepancy was suggested to represent age-related changes in the rate of clearance of AII from the circulation of developing rats.

After incubation of ${ }^{125} \mathrm{I}$-AII with tissue extracts, the majority of the radioactivity appeared as ${ }^{125} \mathrm{I}$-Tyr, suggesting complete hydrolysis of AII. The results suggest that a complex enzymatic mechanism is involved in the hydrolysis of AII in the tissue extracts and plasma. The profile of metabolites observed in incubates of kidney and liver was similar to that reported for plasma, in which an aminopeptidase and an endopeptidase contribute to angiotensinase activity $(7,11)$. Previous investigations from our laboratories using Asp ${ }^{1}$-AII blocked at the amino terminus suggest that AII is hydrolyzed in the renal vascular bed largely by an aminopeptidase mechanism with lesser participation by an endopeptidase (10). The design of the present experiments does not permit further conclusions concerning the mechanism of hydrolysis of AII in the tissue preparations examined.

Further evidence for the complete hydrolysis of AII in plasma and in systemic capillary beds has been provided in the dog (10). When dog plasma was incubated with AII labeled with ${ }^{14} \mathrm{C}$ at the 5-Ile position, free ${ }^{14} \mathrm{C}$-Ile accounted for $90 \%$ of the total metabolites (10). The tryptic and chymotryptic peptide fragments represented only very minor portions of the peptide metabolites. Similar results were observed when $\operatorname{Asp}^{1} 1\left({ }^{14} \mathrm{C}\right)$-Ile ${ }^{5}$-AII was perfused through the renal vasculature of the $\operatorname{dog}(10)$. The data in rats extend this observation to suggest the complete digestion of AII in all tissues and ages examined.

When comparing the half-life of ${ }^{125} \mathrm{I}-\mathrm{AII}$ in the various tissues, 


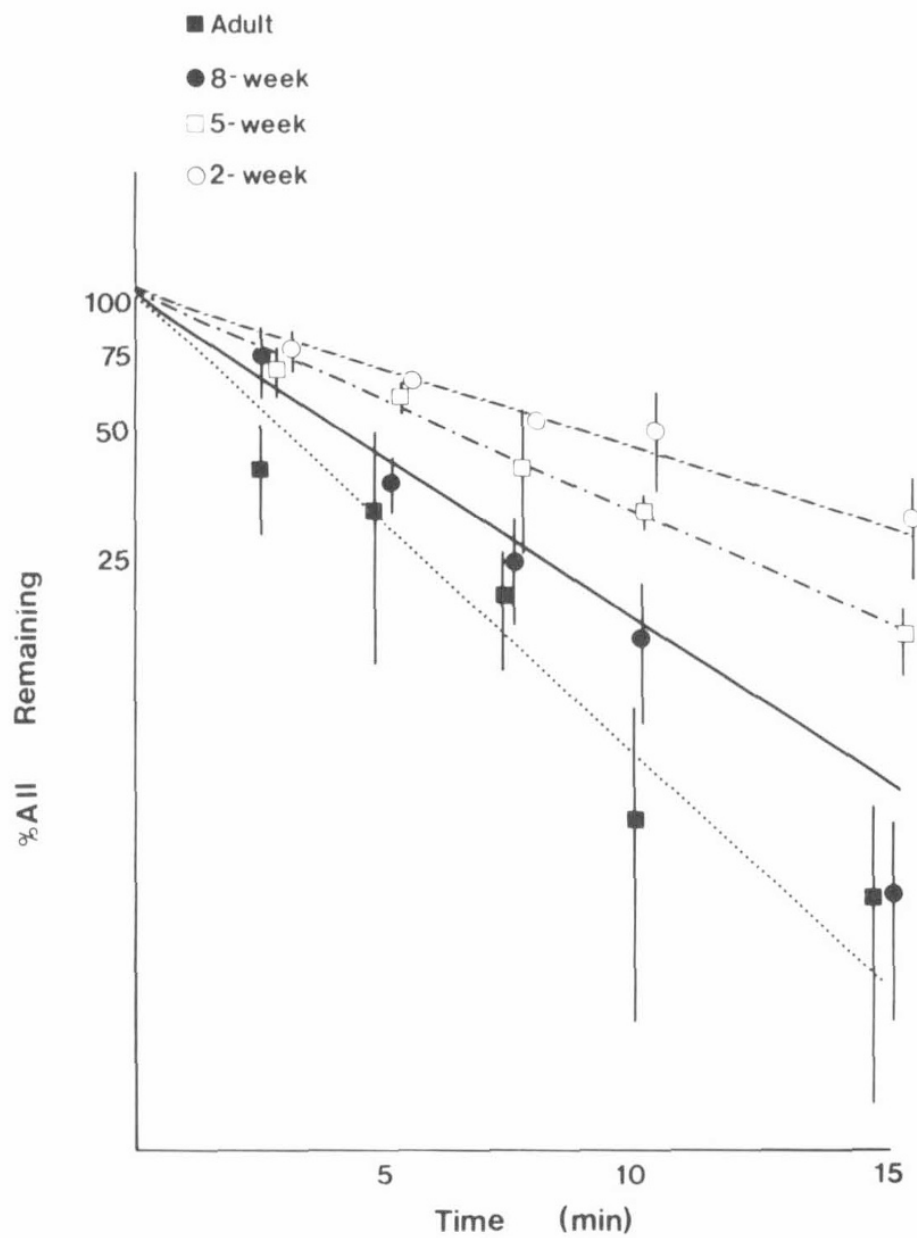

Fig. 2. Disappearance of ${ }^{125} \mathrm{I}$-AII from the incubation medium containing renal tissue from developing rats. The initial ${ }^{125} \mathrm{I}$-AII concentration was adjusted to $100 \%$. Points, mean \pm S.E. of three determinations using tissue from different animals for each measurement. All lines were drawn by linear regression, the method of least squares.

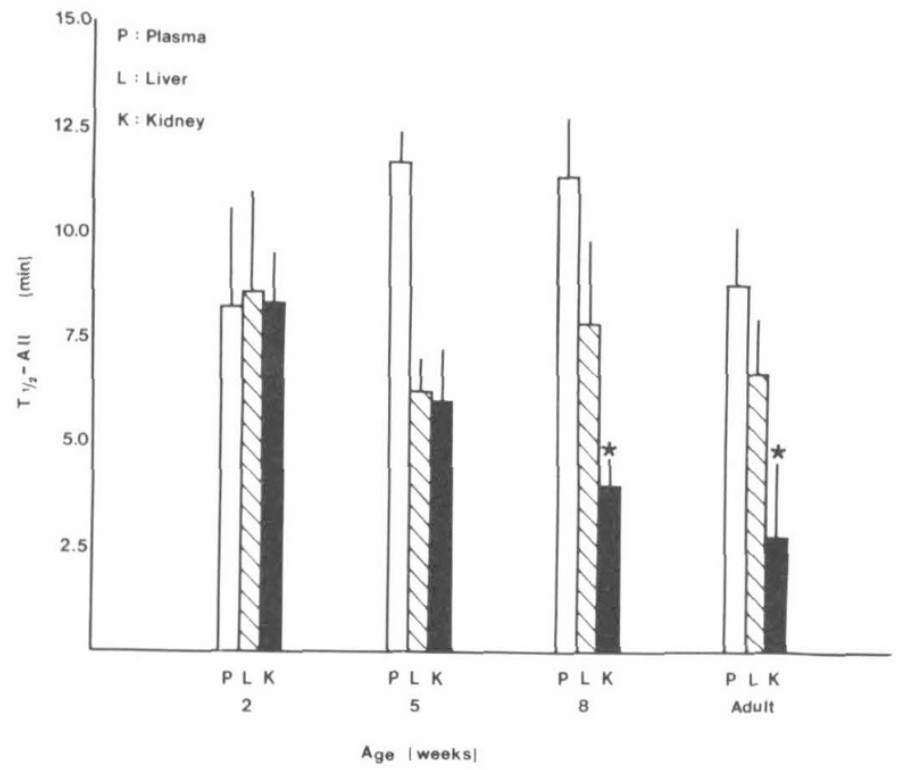

Fig. 3. Age-related changes in the half-life of ${ }^{125} \mathrm{l}$-AII $\left(\mathrm{T}_{1 / 2}\right.$-AII $)$ in various tissues. Plasma was diluted to $1 / 10$ in the final reaction mixture. Hepatic and renal tissues were incubated at $0.5 \mathrm{~g} /$ liter (1:2000 dilution). The half-life of AII was determined from the slope of the disappearance curves. Bars, mean \pm S.E. of three individual determinations. ${ }^{*}$, significant difference compared to 2-wk-old rats.

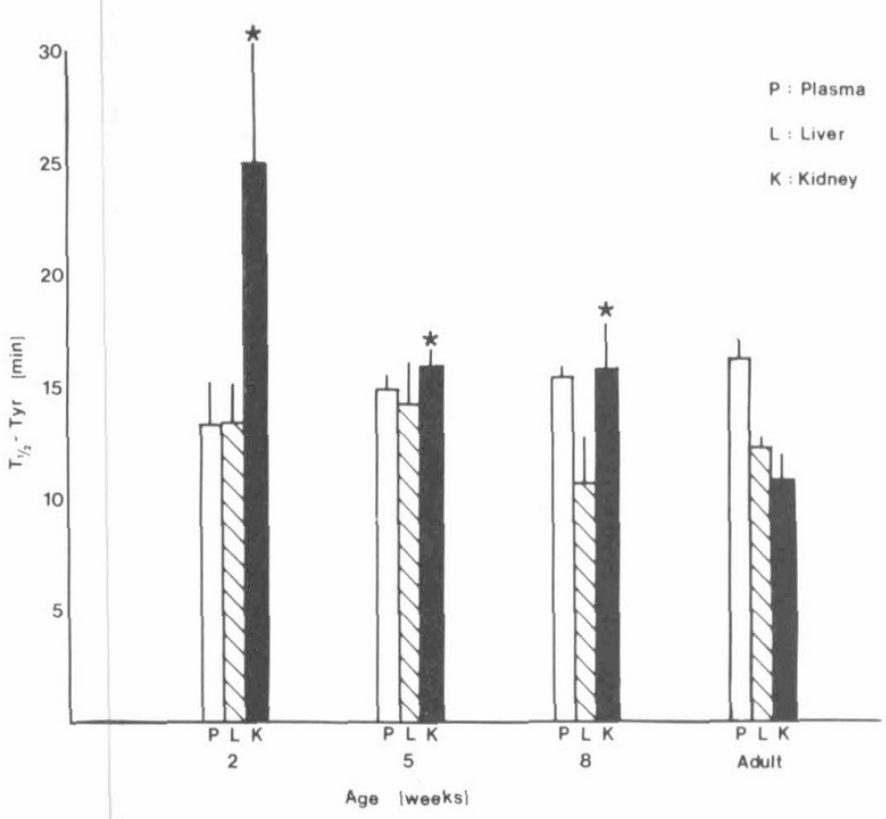

Fig. 4. Age-related differences in the time required for ${ }^{125} \mathrm{I}-\mathrm{Tyr}$ to represent $50 \%$ of the total radioactivity $\left(\mathrm{T}_{1 / 2}-\mathrm{Tyr}\right)$ in the reaction mixture. $\mathrm{T}_{1 / 2}$ - $\mathrm{Tyr}$ was determined from the slope of the line describing the appearance of ${ }^{125} \mathrm{I}-\mathrm{Tyr}$ in the medium. Bars, mean $\pm \mathrm{SE}$ of three individual determinations. *, significant difference compared to adult animals.

it is important to note that plasma was diluted 10 -fold $(100 \mathrm{ml} /$ liter) in the final reaction mixture whereas homogenates of both liver and kidney were incubated at a final concentration of $0.5 \mathrm{~g} /$ liter (1:2000 dilution; w/v). Therefore, the relevance of these data to the in vivo situations is appreciated only after considering these large differences in the dilution of the enzymes. Accordingly, it is concluded that both renal and hepatic tissue are capable of metabolizing AII at rates far in excess of that possible in plasma. Oparil and Bailie (10) found that AII was rapidly hydrolyzed during a single pass through the renal circulation. Because the activity of angiotensinase enzymes in plasma was insufficient to account for the rapid rate of degradation, this transrenal clearance of AII was attributed to peptidases within the kidney parenchyma which rapidly cleave circulating AII (10). Comparison of the distribution of peptide fragments in renal venous effluents to that which results from in vitro incubation of AII in plasma demonstrated a similar profile of peptide products (10). Although much evidence has accumulated concerning angiotensinases, it is not yet certain whether angiotensin is inactivated exclusively extracellularly or if AII is first taken into the cell before its degradation by intracellular enzymes $(6,7,10)$. It was concluded, therefore, that although disruption of cell membranes during homogenization releases intracellular peptidases, results gained from such cell-free preparations provide a relatively accurate reflection of that which occurs in intact tissues.

Broughton-Pipkin (1) reported that the transhepatic passage of AII in adult rabbits resulted in a substantially greater loss of pressor activity than that lost during perfusion of immature rabbit livers. Using similar bioassay techniques for quantifying AII, Pohlova and Jelinek (12) described an age-related increase in the rate of inactivation of AII during incubation with low-speed supernatants of rat kidney homogenates. The inability to demonstrate an age-related difference in the hepatic metabolism of AII in the present experiments may be due either to species differences or to differences in experimental design. Broughton-Pipkin (1) infused AII alternately into the jugular and hepatic portal vein of rabbits. The transhepatic removal of AII was calculated by comparing the systemic pressor response after infusion of AII via the two routes. This experimental design, however, does not discriminate between age-related differences in whole organ perfusion, the sequestration of angiotensin in tissues, receptor occupancy, or differences in the sensitivity of vascular receptors to AII. Electro- 
phoretic separation of peptide fragments, on the other hand, provides a direct quantitative measure of hydrolytic products and thus, differences can be attributed exclusively to age-related changes in the activities of tissue peptidase enzymes.

The age-related increase in the rate of degradation of AII by renal extracts is consistent with the two-fold decrease in plasma AII concentration in rats between 6 and $8 \mathrm{wk}$ of age (19). Pulmonary converting enzyme activity increases, and renin activity remains constant during this period $(17,19)$, both of which are inconsistent with the decrease in plasma AII concentration. Furthermore, several other factors such as increase in tissue mass and organ perfusion or redistribution of cardiac output may complement the effect of an increasing angiotensinase activity. For instance, the increase in both plasma volume and liver mass with age is associated with parallel increases in the total amount of hydrolytic enzymes available for the inactivation of circulating AII. In the case of renal tissue, the increase in renal mass with age complements the increase in the rate of degradation of AII, expressed per gram kidney, thereby augmenting the age-related increase in the clearance of AII by renal parenchyma. The fact that the age-related increase in the rate at which AII is degraded is the only available evidence consistent with the decrease in plasma AII concentration between 6 and 8 wk of age suggests that tissue angiotensinases may be important determinants limiting the circulating concentration of AII in plasma of developing animals.

\section{REFERENCES AND NOTES}

1. Broughton-Pipkin. F. B.: Hepatic inactivation of val ${ }^{5}$-angiotensin $\mathrm{Il}$ amide (hypertensin), val ${ }^{\hat{3}}$-angiotensin II free acid and adrenalin in immature and adult rabbits. J. Physiol. (Lond.), 225: 35 (1972).

2. Broughton-Pipkin, F. B., Lambers, E. R.. and Mott, J. C.: Factors influencing plasma renin and angiotensin II in the conscious pregnant ewe and its foetus. J. Physiol. (Lond.), 243: 619 (1974).

3. Broughton-Pipkin, F. B.. Mott, J. C., and Roberton, N. R. C.: Angiotensin II-like activity in circulating arterial blood in immature and adult rabbits. J. Physiol. (Lond.). 218: 385 (1971).

4. Granger, P., Rojo-Ortega, J. M., Casado-Perez, S., Boucher, R., and Genest, J. The renin-angiotensin system in dogs. Can. J. Physiol. Pharmacol., 49: 134 (1971).

5. Hayduk, K.. Krause, D. K., Heunges, R., and Umbelhaum, V.: Plasma renin concentration at delivery and during the newborn period in humans. Experientia, 28: 1489 (1972).

6. Itskovitz. H. D.. and Miller. L. D.: Differential studies of angiotensinase: activities from several tissue sources. Am. J. Med. Sci., 254: 659 (1967).

7. Khairallah, P. A.. Bumpus, F. M.. Page, I. H., and Smeby, R. R.: Angiotensinase with a high degree of specificity in plasma and red cells. Science (Wash. D.C.). 140: 672 (1963).

8. Matsunaga, M.. Saito, N., Kira, J.. Ogino. K.. and Takayasu, M.: Acid angiotensinase as a lysosomal enzyme. Jpn. Circ. J.. 33: 545 (1969).

9. Mott. J. C.: The place of the renin-angiotensin system before and after birth. Br. Med. Bull., 31: 44 (1975)

10. Oparil, S., and Bailie, M. D.: Mechanism of renal handling of angiotensin II in the dog. Circ. Res. 33: 500 (1973).

11. Pickens, P. T., Bumpus, F. M., Lloyd. A. M.. Smeby, R. R., and Page, I. H.: Measurement of renin activity in human plasma. Circ. Res., 17:438 (1965).

12. Pohlova. I., and Jelinek, J.: Components of the renin-angiotensin system in the rat during development. Pfluegers Arch. Eur. J. Physiol.. 351: 259 (1974).

13. Sokal. R. R., and Rohlf. F. J.: Biometry, W. H. Freeman \& Co., San Francisco. (1969).

14. Stalcup, S. A., Pang. L. M., Lipset, J. S.. Odya, C. E., Goodfriend. T. L., and Mellins, R. B.: Gestational changes in pulmonary converting enzyme activity in the fetal rabbit. Circ. Res., 43: 705 (1978).

15. Trimper, C. and Lumbers, E.: The renin-angiotensin system in foetal lambs. Pflugers Arch. Eur. J. Physiol., 336: 1 (1972).

16. Wallace, K. B., and Bailie, M. D.: Age-related differences in the kinetics of the renin-substrate reaction in rat plasma. (submitted for publication).

17. Wallace, K. B., Bailie, M. D., and Hook, J. B.: Angiotensin-converting enzyme in developing lung and kidney. Am. J. Physiol., 234: R141 (1978).

18. Wallace. K. B.. Bailie, M. D., and Hook, J. B.: Development of angiotensinconverting enzyme in fetal rat lungs. Am. J. Physiol., 236: R57 (1979).

19. Wallace. K. B., Hook. J. B., and Bailie, M. D.: Postnatal development of the renin-angiotensin system in rats. Am. J. Physiol., 238: R432 (1980).

20. Wallace, K. B., Roth, R. A., Hook, J. B., and Bailie, M. D.: Age-related differences in angiotensin I metabolism by isolated. perfused rat lungs. Am. J. Physiol., 238: R395 (1980).

21. Wigger, H. J., and Stalcup, S. A.: Distribution and development of angiotensin converting enzyme in the fetal and newborn rabbit: an immunofluorescence study. Lab. Invest. 38: 581 (1978).

22. The present address of Dr. M. D. Bailie is: Department of Pediatrics, University of Kansas Medical Center. Kansas City, KS 66103 (USA).

23. The authors express sincere appreciation to B. Bowdoin and C. Beall for performing the electrophoresis.

24. Requests for reprints should be addressed to: Michael D. Bailie. M.D.. Ph.D. Department of Pediatrics, University of Kansas Medical Center. Rainbow Boulevard at 39th Street, Kansas City, KS 66103 (USA).

25. This research was supported by NIH Grants HD 06290 and HL22544.

26. Received for publication July $25,1980$.

27. Accepted for publication November 25, 1980. 